\title{
THE EFFECT AND MECHANISM OF URBAN DOMESTIC SEWAGE SECONDARY STERILIZATION BY MICROWAVE
}

\author{
ZHOU, Y.J. \\ School of Physic and Electronic Engineering, Xianyang Normal University \\ Xian yang, Shaanxi 712000, China \\ e-mail: hoozyj@tom.com; phone:+86-1822-0095-253 \\ (Received $8^{\text {th }}$ Mar 2019; accepted $21^{\text {st }}$ May 2019)
}

\begin{abstract}
The interactions between electromagnetic field and the biological system can lead to the change of biological morphology, structure, function and other aspects at the different levels of biological targets. The domestic sewage is secondarily disinfected using continuous electromagnetic waves, the microscopic molecules have a certain dipole-moment and the biological molecular aggregates with dielectric properties of the cell may generate dielectric loss under the effect of the applied electromagnetic field. The thermal effect will be produced by putting the microwave energy into the heat of irregular movement which increases biological system's temperature. Under the influence of an applied electromagnetic field, the membrane potentially undergoes conformational changes that would affect $\mathrm{K}^{+}$ ion, $\mathrm{Na}^{+}$ion channels open and make the voltage-dependant $\mathrm{Ca}^{2+}$ ion open, the high concentration of $\mathrm{Ca}^{2+}$ ion of the membrane into the cell along the potential gradient, which leads to cell death, resulting in the biological non-thermal effects, the greater the changes of cellular transmembrane voltage, the higher the rate of cell death. The experiment results show that the microwave secondary sterilization has a good sterilizing effect, the method has the advantages of high efficiency, low cost, simple operation, easy automation, without adding any substance and does not produce any secondary pollution, etc.

Keywords: electromagnetic field, biology system, biological morphology, microscopic molecular, high efficiency
\end{abstract}

\section{Introduction}

Water is an indispensable natural resource in human production and life, and also an important factor in promoting social development and promoting the progress of civilization. The reform and opening up has made China's economic achievements a great achievement. The people's living standards are getting higher and higher, the urban population is also increasing, the demand for water resources is increasing, and the same domestic sewage discharge is also increasing. China is actually a relatively scarce water resource with low per capita possession, which is a country with severe water shortage.

The application of domestic sewage treatment and reuse technology has historical significance for solving water shortage and environmental pollution. On the one hand, domestic sewage treatment reduces domestic sewage discharge, which is very beneficial to avoid water eutrophication and water pollution caused by water pollution, and greatly reduces the cost of water pollution control. On the other hand, the treatment and reuse of sewage will help people solve the problem of water shortage, and reuse the reused water for urban greening, landscape hydration and road sprinkling, flushing and car washing, industrial, building fire protection and many other aspects. It has had a tremendous impact on agriculture, industry and people's lives, and promoted the sustainable development of society. However, in the past 100 years, urban domestic sewage treatment technology has been in a state of slow progress, lacking technological innovation and innovation (Zhao, 2016; Patle et al., 2019). 


\section{Current status of urban domestic sewage}

\section{Urban domestic sewage characteristics}

Urban domestic sewage contains high levels of suspended solids, such as food residues, grease and other types of domestic waste, which cause the color of the sewage to be heavy. In addition, because there are many organic residues such as food residues contained in urban domestic sewage, when the organic matter rots, it will produce extremely heavy odor and cause the most direct pollution to the environment. In addition, laundry wastewater, because of detergent, generally contains phosphorus and nitrogen. It is easy to cause eutrophication of water bodies. Hospital wastewater may carry a large number of pathogenic microorganisms.

\section{Urban domestic sewage source}

Urban domestic sewage mainly comes from wastewater generated by urban residents in daily life. It includes various sewer waste water, washing wastewater, toilet wastewater, hospital sewage, rainwater, etc., which are discharged from living quarters, schools, hospitals, shopping malls, hotels, etc. (Mcleod and Liboff, 1986; Sen et al., 2018). The source is extensive, and the source domestic sewage discharge management is not standardized. The amount produced is large, unstable, and has obvious seasonality.

\section{Urban domestic sewage impact}

In general, the hazards of urban domestic sewage at this stage are mainly reflected in the following aspects:

1) The eutrophication of water bodies, with the discharge of domestic sewage, a large amount of organic substances, chemical substances, metal substances, etc., and the increase of chemical substances such as nitrogen and phosphorus substances will pollute the water bodies, resulting in eutrophication of water bodies (Huang, 2000; Yahya et al., 2018). There may even be red tides and the like;

2) Polluted urban environment, some domestic sewage has odor. If it is not treated in time, it will be stinking, directly polluting the urban environment, causing troubles for people's daily life and work. In addition, odor Diffuse can endanger the health of the human body and affect the development of green cities;

3) Affecting groundwater sources. At this stage, due to the complexity of the composition of urban domestic sewage, various chemical substances may be mixed together to produce some chemical reactions, which may cause some toxic substances, if not treated in time (Durney et al., 1988; Suhaili and Samsudin, 2018). It will cause toxic substances to enter the groundwater and urban residents' water, causing residents to poison, directly threatening the life and health and personal safety of urban residents. There are also a large number of pathogenic microorganisms in urban domestic sewage. It poses a great threat to people's health and so on.

Domestic sewage sterilization is an important process to ensure the health and safety of domestic sewage (Lednev, 1991; Kasim et al., 2019). Generally the sterilization methods to water are chlorine, chlorine dioxide, ozone, etc, in which the chlorine is a common method which has the characteristic of low cost, simple process and easy to operate, but the chlorine has powerful oxidation and easy to acting with organic matter 
in water to produce halogenated hydrocarbons, chloroform and PCBs that is harmful to people and animals (Zhang, 2002; Tao, 2018). The effect of chlorine dioxide sterilization is better than chlorine and will not easy produce organochloride, but chlorine dioxide is unstable and sensitive to temperature, pressure and light. It is easy to explosive when it meets fire or organics. So it only be produced and used on the spot (Chen and Wang, 2001; Jamil et al., 2018). Ozone has strong oxidation ability, fast, good sterilization effect and not produces odor smell, but the Ozone treatment requires high technique, complicated equipment and high energy (Jin, 1999; Nawaz et al., 2018).

Microwave treatment has unique advantages. The material is heated by way of molecule polarization or ion- conduction effect through microwave. The heated polar molecule or ions rapid motion and orientation in the electromagnetic field which leads to heat by the tearing and mutual friction ( $\mathrm{Li}$ and Niu, 1990; Austin et al., 2018). Microwave can kill various microorganisms. The thermal effect and mechanism of microwave have been a fact which is widely accepted by people, but there still exists the big dispute to the mechanism of non-thermal effects of electromagnetic (Liboff and Mcleod, 1988; Ismail et al., 2019). The work describes the sterilization effect of microwave to domestic sewage and analyze the phenomena and mechanism of microwave sterilization from the experimental and theoretical (Yang, 2018).

\section{Experiment apparatus and method}

It shows the related experimental equipment 1 (Fig. 1) and the related experimental equipment 2 (Fig. 2).

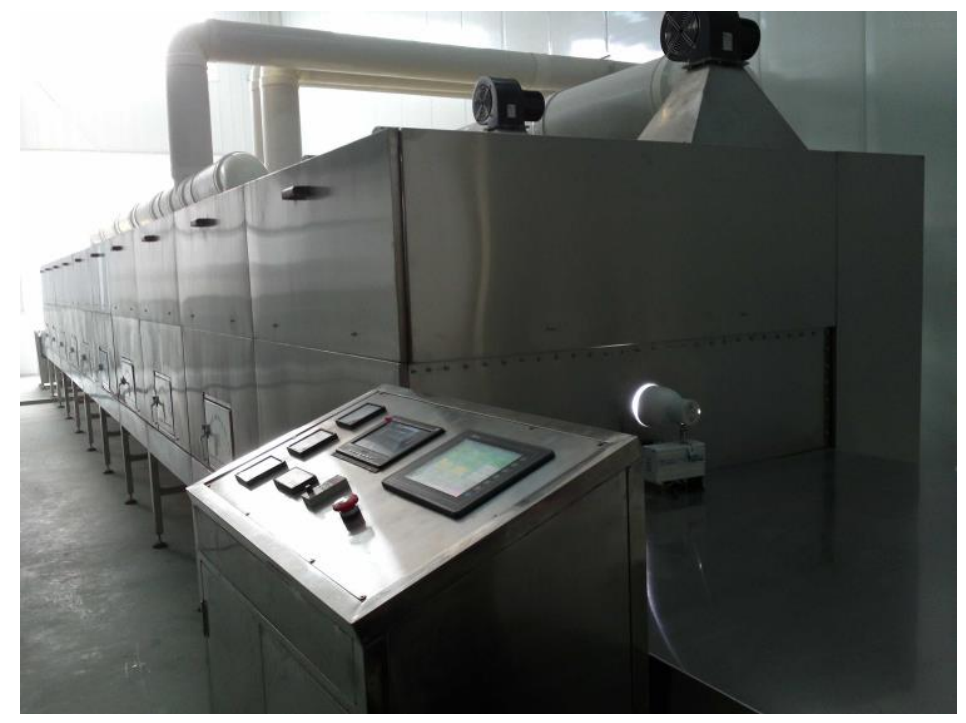

Figure 1. The related experimental equipment 1

The domestic sewage is taken from the domestic sewage well of xianyang normal University living quarters and the water $\mathrm{pH}$ 's value is $7.3 \sim 7.8$, the domestic sewage has been treated by bio-oxidation, then be disinfected by microwave, the total amount of bacteria and fecal coliform was decreases with the suspended solids significantly reduce in domestic sewage (Zhou and Zhang, 2000). However, the concentration of the two kinds of germs was still so high that it must be disinfected before discharge. The 
continuous microwave is used to disinfect to domestic sewage which has been treated by bio-oxidation in the experiment (Niu et al., 2002). It shows the principle chart of electromagnetic radiation (Fig. 3). The microwave frequency is better to be higher (Zhang, 1998), taking into account the depth of penetration and other reasons, the microwave frequency is $2450 \mathrm{MHz}$ and the average power density is $520 \mathrm{MW} / \mathrm{cm} 2$ was adopted in this experiment.

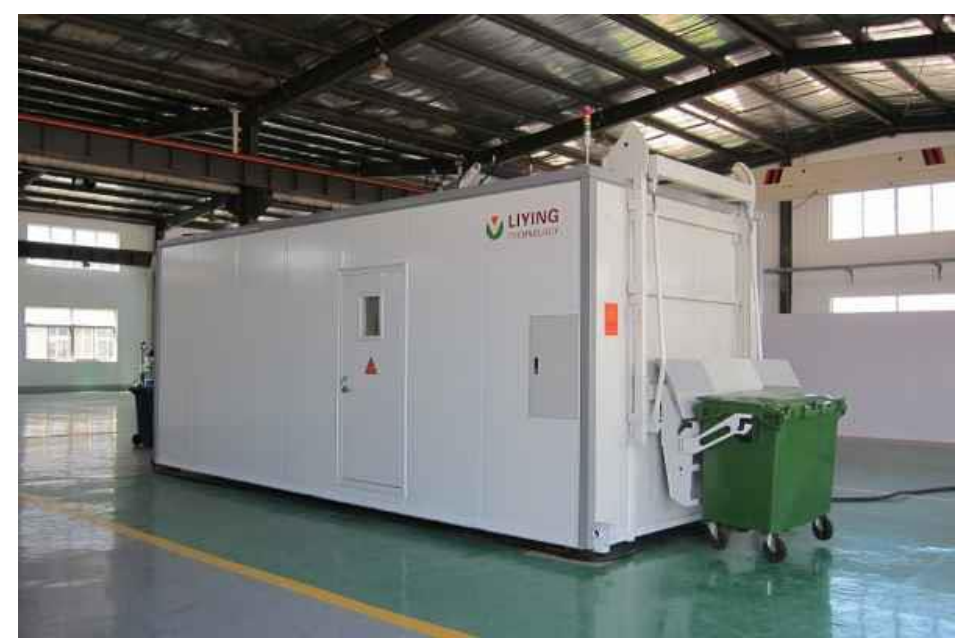

Figure 2. The related experimental equipment 2

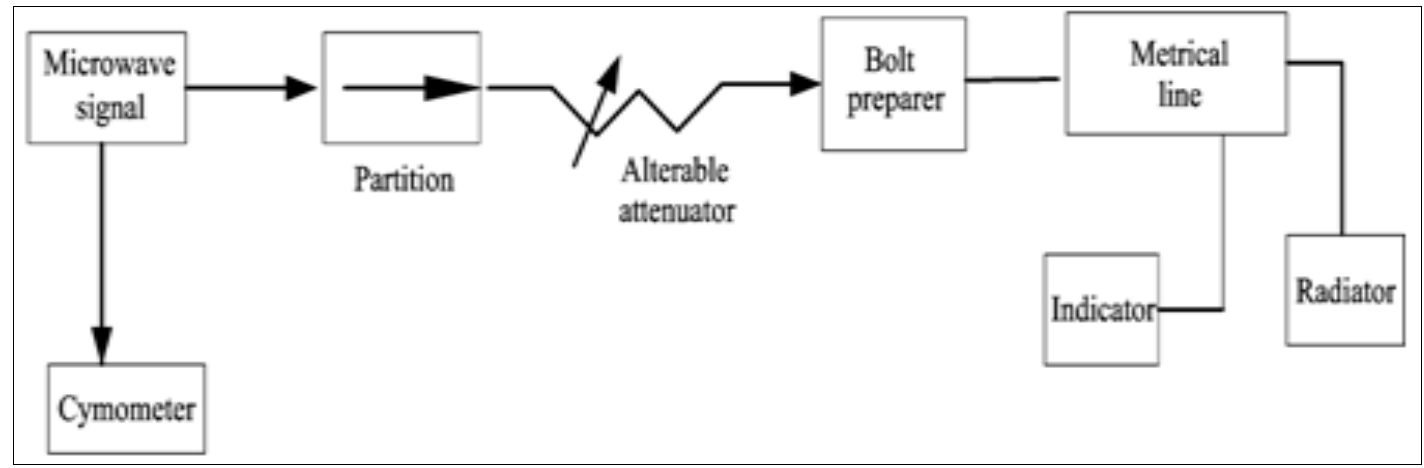

Figure 3. The principle chart of electromagnetic radiation

It shows the schematic diagram of domestic sewage sterilization (Fig. 4). The diameter of waterpipe is $15 \mathrm{~mm}$; length of $2 \mathrm{~m}$ insulated wire wound on a $20 \mathrm{~cm}$ long pipeline. The water samples which have different domestic sewage quality were processed by microwave under the identical condition then placed it into incubator about $24 \mathrm{~h} 48 \mathrm{~h}$ ( $\mathrm{Lu}$ et al., 1996). The plate culture method using detects the number of germs. Three groups constitute a parallel sample contain and each group has three subsets sample. The same water quality domestic sewage as comparison sample, which isn't treatment by microwave. An 828 type $\mathrm{pH}$ 's apparatuses measure the $\mathrm{pH}$ value before and after the sample treated by microwave. It lists the total germs and the corresponding sterilization rate at 40 mins (Table. 1). It lists the sterilization rate at 
different time (Table 2). The temperature in the experiment course is controlled within $(25 \pm 1){ }^{\circ} \mathrm{C}$.

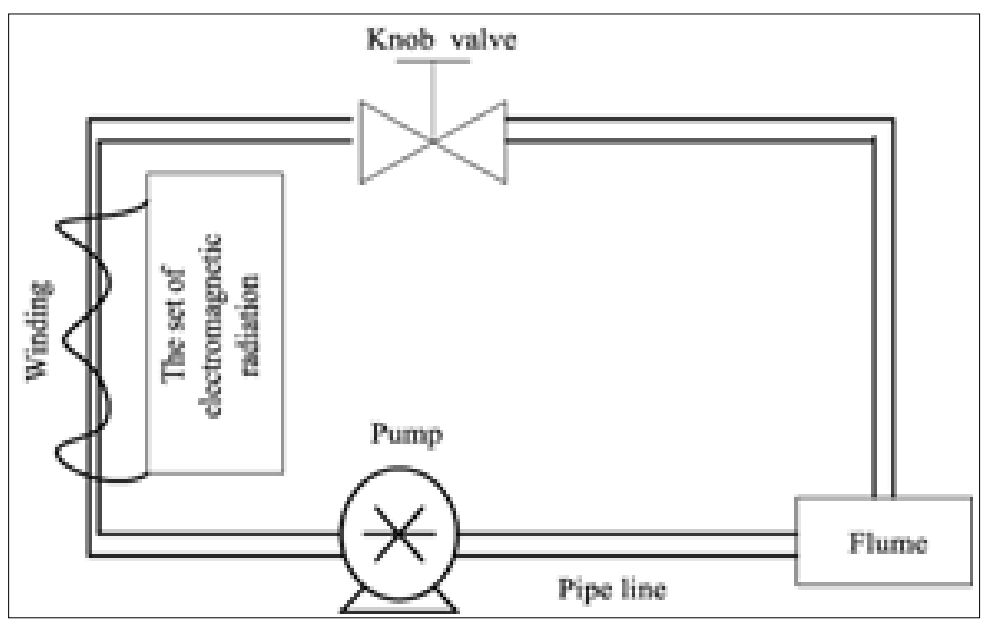

Figure 4. The schematic diagram of domestic sewage sterilization

Table 1. Sterilization effect under different water quality conditions

\begin{tabular}{c|c|c|c}
\hline Sample number & $\begin{array}{c}\text { The sum of bacteria in original } \\
\text { sample (Entries/mL) }\end{array}$ & $\begin{array}{c}\text { The sum of bacteria in worked } \\
\text { sample (Entries/mL) }\end{array}$ & $\begin{array}{c}\text { The efficiency of kill } \\
\text { bacteria / \% }\end{array}$ \\
\hline 1 & $3.5 \times 10^{6}$ & $3.5 \times 10^{4}$ & 99.0 \\
2 & $4.9 \times 10^{6}$ & $3.0 \times 10^{4}$ & 99.3 \\
3 & $5.3 \times 10^{6}$ & $3.2 \times 10^{4}$ & 99.4 \\
4 & $1.5 \times 10^{7}$ & $5.1 \times 10^{4}$ & 99.7 \\
\hline
\end{tabular}

Table 2. Sterilization effect under different times

\begin{tabular}{c|c|c|c|c|c}
\hline \multirow{2}{*}{ Sample } & \multicolumn{5}{|c}{$\boldsymbol{t} / \mathbf{m i n}$} \\
\cline { 2 - 6 } & $\mathbf{0}$ & $\mathbf{1 0}$ & $\mathbf{2 0}$ & $\mathbf{3 0}$ & $\mathbf{4 0}$ \\
\hline 1 & $3.2 \times 10^{6}$ & $1.92 \times 10^{6}$ & $8 \times 10^{5}$ & $3.2 \times 10^{4}$ & $2.56 \times 10^{4}$ \\
2 & $3.7 \times 10^{6}$ & $2.294 \times 10^{6}$ & $8.88 \times 10^{5}$ & $2.96 \times 10^{4}$ & $2.59 \times 10^{4}$ \\
3 & $5.0 \times 10^{6}$ & $2.85 \times 10^{6}$ & $1.25 \times 10^{6}$ & $5 \times 10^{4}$ & $3 \times 10^{4}$ \\
4 & $1.9 \times 10^{7}$ & $1.045 \times 10^{7}$ & $4.37 \times 10^{6}$ & $7.6 \times 10^{4}$ & $4.75 \times 10^{4}$ \\
\hline
\end{tabular}

\section{The result and discussion}

The total amount of germs and the sterilization rate of four kinds of water samples disinfected by microwave at 40 mins are listed in Table 1. It can be seen from Table 1 that the sterilization rate of samples 1 to 4 over reaches $99 \%$, but the electromagnetic sterilization effect of sample 4 is better than sample 1. The data in Table 2 are obtained for samples irradiated by microwave at different time and the trend of the data is the same, that is, with increasing of irradiation time, the higher sterilization rate (Yanyan et al., 2019). However, different samples have different sterilization rate at the same time. For example, it can be seen from sample 1 and sample 2, the efficiency of sterilization rate of sample 1 is about $57 \%$ at 20 mins, while the sample 2 is $76 \%$ at the same time. The different sterilization rate between samples may be due to, first, different water 
samples contained different amounts of bacteria before sterilization. Second, different water samples contained different kinds of bacteria, and thus the electric parameters (permittivity $\varepsilon$, conductivity $\sigma$ ) are different. So microwave energy absorbed is different. In generally, the stronger the microwave energy absorption of bacteria, the better the sterilization rate. If the sample has more fungi, shapeless spores and thermophilric bacteria, then it needs more time to reach the same sterilization effect (Kang, 2018). Therefore, under the same condition, the fewer the sample contained the fungus talked above, the better sterilization effect. The fittest $\mathrm{pH}$ value to most bacteria is 7.3 7.8. The $\mathrm{pH}$ value of the sample before and after sterilization had been test with 828 type $\mathrm{pH}$ 's tester. The $\mathrm{pH}$ value before sterilization is about 7.4, while after sterilization it is about 7.5. Thus it can be seen that the $\mathrm{pH}$ value of sample has slightly changes before and after sterilization, but still between 7.3 7.8. Therefore, the influence brought by the pH value slightly change can be neglected (Li et al., 2019).

\section{Analysis of the mechanism}

\section{The mechanism of heating effect}

A material may be having many dielectric mechanism or polarization influence. In fact, material loss can be expressed as dielectric loss and conduction loss caused by the electrical conductivity $(\sigma)$, namely:

$$
\varepsilon_{\mathrm{r}}^{\prime \prime}(\omega)=\varepsilon_{\mathrm{r}}^{\prime \prime}+\frac{\sigma}{\omega \varepsilon_{\mathrm{o}}}
$$

Under the action of the electromagnetic wave, the electromagnetic energy is absorbed by material

$$
P=\frac{1}{2} \omega \varepsilon_{\mathrm{rd}}^{\prime \prime} \int_{\mathrm{v}}|E|^{2} \mathrm{~d} v
$$

where $\varepsilon_{r d}^{\prime \prime}$ is dielectric loss of the material, $\omega$ is the frequency of electromagnetic wave, and $\mathrm{E}$ is the electric field strength.

There exists mass water inside every life body, which distributed in all parts of the living body such as cell membrane, cytoplasm, cell nucleus, cells, tissues, blood and lymph liquid water molecules is polar molecule which has the bigger dipole moment (Cheng and Lin, 1981). At the subcellular level, the orderly biomolecule gathered body also showed significant dielectric properties, such as cell membrane which is bilayer structure dielectric material composed of the lipid molecule. All membrane dipole moments can be fully polarized under the transmembrane resting potential difference and maintain a certain conformation. The force to maintain the conformation of macromolecules primarily is the static electricity of intermolecular and intramolecular (including interaction between dipole and dipole) and other interaction force (for example: van der Waals force). Under the effect of microwave, the negative charges of molecule are distributed again that leads to the change itself of dipole moment and polarization state, which may induce the change of molecule construction. The displacepolarization time of general material establishes needs about 10-16--10-12 s, which can be neglected in microwave scope (microwave priod is 10-9--10-12 s). However, the dipole needs long time which over 10-10 s. For example, water molecules have a strong 
intrinsic dipole moment and its relaxation time is $0.25 \times 10-10 \mathrm{~s}$ which justly in the scope of microwave, therefore the attenuation effect of water to microwave is bigger than the general material (Zhai et al., 1998), The polarization would appear hysteresis phenomenon which produce the dielectric loss. With the dielectric method of time domain reflection, it has been found that there has significant dielectric loss in the vicinity of $10 \mathrm{MHz}$ when natural DNA was dissolved degeneration (Richard and Stephen, 1998). It can be seen that the thermal effect is more notable at the condition of a higher frequency and a bigger of from the Equations 1 and 2 under the affection of microwave. These dipoles constantly change from one equilibrium state to another equilibrium state, a molecule dipole would frequently colliding with surrounding other molecules in this course, thus the microwave energy consumed and converted into heat. When the temperature exceeds the temperature of microbes to survive, it will lead to germ death, which is identical to the mechanism of pasteurization $(\mathrm{Li}, 2018)$.

\section{The mechanism of non-heating effect}

The microwave non-heating mechanism of the body has related discussion (Liu and Wang, 2003), but there is no unified knowledge and many kinds of hypothesis are put forward. Main hypothesis such as cell membrane perforation effect, Ion cyclotron resonance model, Ion parametric resonance model, State parameter representation, an electromagnetism mechanism model ect. The cell membrane perforation effect argues that the cell membrane is a kind of phospholipid bilayer construction which has certain permeability, a certain degree of toughness and a certain charge is absorbed to the surface. Therefore, there has certain potential difference between the inner and outer surface of membrane. The potential difference will be enlarged when an electric field is applied membrane, at this time the permeability of cell membrane also increases. The permeability of cell membrane would dramatic increase and many holes will appear on the membrane which reduces the toughness of membrane when the electric field strength to the critical value. Since the special structure of the cell membrane, it will produce an adaptive adjustment trying to maintain the original way of life, the membrane can control the outside influences within the capacity of the adaptive and the life living with original method ( $\mathrm{Li}$ et al., 2019). If the outside influences exceed the body's adaptive capacity, which may produce the variations and lead to new existence method. If outside influences exceeded the limit of adaptation, it will destroy the original structure of membrane and lose their function can't be restored, thus cell death. The experiment proves there has clear rift on the cell after the yeast was killed (Jayaran et al., 1994). Though bacterial cell structure is small but there no essential difference of internal structure between general biological cell and bacterial cell. The main effect of electromagnetic wave on the cell is at the cell membrane. Under the condition of resting, the transmembrane resting potential difference of cell membrane is $60 \sim 100 \mathrm{mV}$, which is mount to $107 \mathrm{~V} / \mathrm{m}$ strong electric field, therefore all dipole moments of the membrane can be full polarization under the strong electric field action. Therefore, it is not hard to understand the electromagnetic field can play significant effect on the membrane (Shan et al., 2018).

With the spherical cell as the research object, the transmembrane voltage Uion is formed due to ion accumulation and transmembrane transport both side of the membrane under the resting state, the Uion value can be calculated from the Goldman's equation (Plonsey and Barr, 2000). 


$$
U_{\text {ion }}=\frac{R T}{F} \ln \frac{P_{\mathrm{K}}\left[K^{+}\right]_{0}+P_{\mathrm{N}_{\mathrm{a}}}\left[\mathrm{N}_{\mathrm{a}}^{+}\right]_{0}+P_{\mathrm{cl}}\left[\mathrm{Cl}^{-}\right]_{0}}{P_{\mathrm{K}}\left[K^{+}\right]_{\mathrm{i}}+P_{\mathrm{N}_{\mathrm{a}}}\left[N_{\mathrm{a}}^{+}\right]_{\mathrm{i}}+P_{\mathrm{cl}}\left[C l^{-}\right]_{\mathrm{i}}}+\Delta U
$$

In this state, the membrane permeability to $\mathrm{K}^{+}$ion is much larger than $\mathrm{Ca}^{2+}$ ion and $\mathrm{Na}^{+}$ion. At this moment the ion channels are closed to $\mathrm{Ca}^{2+}$ ion and $\mathrm{Na}^{+}$ion. Under the applied additional alternating electric field $\mathrm{E}$, the interior cytoplasm and the external medium of the cell as good conductor and the cell membrane as a dielectric. The induced transmembrane voltage UE is superimposed on Uion. According to the classical theory of cell membrane induction electromotive force (Tadej and Damijan, 2000), the induction electromotive force UE is generated on both sides in the cell membrane is

$$
U_{\mathrm{E}}=\frac{3}{2} E_{\mathrm{e}}(t) R \cos \alpha \frac{1}{1+j \omega \tau_{\mathrm{m}}}
$$

where $\operatorname{Ee}(\mathrm{t})$ is outer electric field intensity, $\mathrm{R}$ is the cell radius, $\alpha$ is the angle of between the external electric field direction and the axial of ion channels, $\omega=2 \pi f, f$ is frequency of the applied electric field, and $\tau_{m}$ is the inductive time constant of membrane that can be expressed through first-order system as:

$$
\tau_{\mathrm{m}}=\frac{R C_{\mathrm{m}}}{\frac{2 \lambda_{\mathrm{i}} \lambda_{\mathrm{e}}}{\lambda_{\mathrm{i}}+2 \lambda_{\mathrm{e}}}+\frac{R}{d} \lambda_{\mathrm{m}}}
$$

where $\mathrm{Cm}$ is the equivalent capacitance of the cell membrane, $\lambda_{i}, \lambda_{e}$ and $\lambda_{m}$ is respectively the conductivity of inside and outside of cell membrane and the cell membrane, $d$ is the average thickness of the membrane (Yang, 2018).

From Equations 4 and 5, we know that the amount of change of cell transmembrane potential has relation with the electromagnetic wave field strong and power, has relation with the cell type and size, has relation with the intracellular fluid and extracellular fluid dielectric constant and conductivity ( $\mathrm{Li}, 2018)$. The external electric field causes the membrane voltage change, thereby enabling the ion permeation rate change of the cell membrane. The ion permeation ratio is direct proportional to the change of membrane voltage caused by the external electric field (Zhang et al., 2004). The studies have shown that $\mathrm{Ca}^{2+}$ ion channel is a voltage dependent of membrane. Some kinds of channel activity of $\mathrm{K}^{+}$ion and $\mathrm{Na}^{+}$ion are relation with $\mathrm{Ca}^{2+}$ ion. So the influx of $\mathrm{Ca}^{2+}$ ion may also cause the channel open of $\mathrm{K}^{+}$ion and $\mathrm{Na}^{+}$ion. When the influx volume increasing of $\mathrm{Ca}^{2+}$ ion. The influx of $\mathrm{Na}^{+}$ion is predominated, while the influx of $\mathrm{Ca}^{2+}$ ion can open $\mathrm{K}^{+}$channel that is relies on $\mathrm{Ca}^{2+}$ ion, which make the outflow of $\mathrm{K}^{+}$ dominant. Under the action of an applied electromagnetic field, the external electric field, the cell transmembrane potential increases, when the membrane voltage is increased to a certain value so that the voltage-dependent $\mathrm{Ca}^{2+}$ ion channels open, the larger concentration of $\mathrm{Ca}^{2+}$ ion outside the cell membrane into the cell along the potential gradient (Yang et al., 2018). The experiment and theoretical indicate that the greater the change in cell membrane voltage, the higher the rate of cell death. In addition, from the dielectric properties of the cell membrane to see, the role of the applied voltage causes the inside and outside charge density of cell membrane will 
change. The cell membrane surface charge density and the pressure difference between inside and outside of the cell membrane has the following relationship (Gao et al., 2002)

$$
\Delta P_{\mathrm{E}}=\frac{\left(\sigma_{\mathrm{i}}^{2}+\sigma_{0}^{2}\right)}{2 \varepsilon_{0}}+\frac{\sigma_{0} \sigma_{\mathrm{i}} r_{\mathrm{i}}}{\varepsilon_{0} r_{0}}
$$

where $\sigma_{i}$ is the surface charge density of the inner surface of cell membrane, $\sigma_{0}$ is the surface charge density of the outer surface of cell membrane, $r_{i}$ is the curvature radius of the inner membrane, and $r_{0}$ is the curvature radius of the outer membrane (Hai et al., 2017).

From Equation 6, we know that the greater the surface charge density, the greater the pressure difference between inside and outside of the cell membrane, and thus an impact on the ion channel Open and close (Amit et al., 2017). When the effect of above combination factors exceeds the limits of adaptive of membrane, the original structure of the membrane was destroyed and could not be restored, the cell death, the purpose of sterilization is achieved. The non-heating effect of electromagnetic biological less significant than the thermal effects of electromagnetic biological, it requires a process of accumulation.

\section{Outlook}

With the continuous enrichment of material life, people's demand for domestic water is also increasing. The reserves of water resources on the earth are limited and they are non-renewable natural resources (Yanyan et al., 2019). Urban sewage treatment and reuse can effectively solve the shortage of urban water resources, and at the same time reduce environmental pollution, strengthen water recycling and sewage utilization rate, and achieve sustainable development of urban water resources (Kang et al., 2018). Therefore, in the process of treating urban domestic sewage, it is necessary to adhere to the principle of sustainable development and energy conservation and consumption reduction to ensure that urban domestic sewage treatment technologies and treatment processes can meet these requirements in practical applications (Shan et al., 2019).

The microwave sterilization technology can also serve the domestic sewage treatment well. The pathogens such as worm eggs, enteroviruses and pathogenic bacteria can be killed by using the combined action of the biological heating effect and biological non-heating effect. This method is a physics method, there is no obvious chemical treatment, the composition and structure of water was not change and sterilization fast. Compared with traditional domestic sewage treatment and sterilization technologies such as liquid chlorine, chlorine dioxide and ultraviolet sterilization, microwave sterilization technology not only has high sterilization efficiency, no secondary pollution, broad spectrum of sterilization, no noise, no odor, etc. (Yang et al., 2018). All the advantages of the technology, but also have the advantages of stable control system, long service life, low operating cost, excellent energy saving, safe and reliable, easy maintenance, and the ability to provide residual sterilization (Zhang et al., 2017). In order to better promote the technology, the utilization of microwave energy conversion and the expansion of the application range of microwave technology should be paid attention to by the industry. It should popularize the use of the technology on a 
large scale, so that the technology can gradually replace some traditional technology and sterilization technology in the future life more efficient, environmentally friendly and more convenient for human production and life (Zhang, 2017).

Acknowledgements. This work was funded by Shaanxi Province Science and Technology Research and Development Program, Grant number 2016JM6053, and was funded by Shaanxi Provincial Department of Education special scientific research project, Grant number 18JK0831, and was funded by the research foundation of Xianyang Normal university, Grant number 14XSYK009, and was funded by Xianyang Normal College Teaching Reform Project, Grant number 201402010, and was funded by Shaanxi University Student Innovation and Entrepreneurship Training Program, Grant number 2510, and was funded by Xianyang Normal University Innovation and Entrepreneurship Training Program, Grant number 2017079.

\section{REFERENCES}

[1] Amit, Chandra, R., Ghosh, U. K., Nayak, J. K. (2017): Phycoremediation potential of marine microalga tetraselmis indica on secondary treated domestic sewage for nutrient removal and biodiesel production. - Environmental Science Pollution Research 24(218): $1-8$.

[2] Austin, O. E., Ebuka, A. O., Zanders, A. C. C., Joseph, I. N. (2018): Seismic Analysis Of The Transgressive Systems Tracts (TSTS) Of The Niger Delta. - Earth Sciences Malaysia 2(2): 16-19.

[3] Blanchard, J. P., Blackman, C. F. (1994): Clarification and application of an ion parmetric resonance model for magnetic field interactions with biological systems. Bioelectromagnetics 12: 217-238.

[4] Chen, Y., Wang, X. D. (2001): Using of Ultraviolet Sterilization wastewater treatment. Chongqing Environmental Science 23(3): 49-51.

[5] Cheng, J. J., Lin, K. C. H. (1981): Acta biophysica sinica. - Beijing: People's Education Publisher 36-40.

[6] Durney, C. H., Rushforth, C. K., Anderson, A. A. (1988): Resonant AC-DC magnetic fields: calculated response. - Bioelectromagnetics 315-336.

[7] Gao, Y. Y., Jiao, Q. Y., Fang, J. Z. H. (2002): Electrical Property of Plant Cell Membrane and its Influence. - Cellular Pressure Acta Biophysica Sinica 18(3): 277-281.

[8] Haiquan, W. U., Zhou, L., Sun, F., Luo, X., Lei, N., Wang, J. (2017): Application of biological enhancement technology on treating urban domestic sewage in alpine regions. - Chinese Journal of Environmental Engineering 11(6): 3511-3517.

[9] Ismail, I., Husain, M. L., Satyanarayana, B., Ibrahim, S., Zakaria, R. (2019): Root Density Analysis And Wave Attenuation Ability Of Rhizophora Species At Kemaman, Terengganu. - Earth Sciences Malaysia 3(1): 18-24.

[10] Jamil, F., Arshad, R., Ali, M. A. (2018): Design, Fabrication And Evaluation Of Rotary Hot-Air Dryer For The Value Addition Of Fruit Waste. - Earth Sciences Pakistan 2(2): 07-11.

[11] Jin, Q. H. (1999): Microwave and chemistry, Beijing. - China Technology Publisher: 1315.

[12] Kang, L., Du, H. L., Du, X., Wang, H. T., Ma, W. L., Wang, M. L., Zhang, F. B. (2018): Study on dye wastewater treatment of tunable conductivity solid-waste-based composite cementitious material catalyst. - Desalin. Water Treat. 125: 296-301.

[13] Kasim, S., Hassan, R., Zakaria, Z. (2019): Re-Engineering In Confinement Method. Engineering Heritage Journal 3(1): 18-19.

[14] Lednev, V. V. (1991): Possible mechanism for the influence of weak magnetic field on biological system. - Bioelectromagnetics 12: 71-75. 
[15] Li, J. X., Niu, Zh. Q. (1990): The generality of biologic electromagnetism. - Xi'an: Xidain University Publisher: 125-130.

[16] Li, J. (2018): 2. Income Distribution of Garbage Disposal PPP Project Based on Modified Shapley Value Method. - Argos 35(68).

[17] Li, C., Li, S., Tian, Q. (2019): Microbial Attachment Behavior and Pollutant Removal Performance of Modified Quartz Sand. - Acta Microscopica 28(2).

[18] Liboff, R., Mcleod, R. (1988): Kinetics of channel membrane ions in magnetic fields. Bio-electromagnetics 9: 215-227.

[19] Liu, Y. C. H., Wang, Y. H. (2003): Theoretical Analysis of the Electromagnetic Organism Effect in Killing Bacterium by Electromagnetic Radiation. - Journal of Soochow University (Engineering Science Edition) 23(5): 6-11.

[20] Lu, Z. H. Y., Niu, Z. H. Q., Ma, J. G. (1996): A Study on Killing Germs in Traditional Chinese Medicines by means of Microwaves. - Journal of Microwaves 12(2): 155-158.

[21] Mcleod, R., Liboff, R. (1986): Dynamic characteristics of membrane ions in multifield configurations of low-frequency electromagnetic radiation. - Bioelectro magnetics 7: 177-189.

[22] Nawaz, A., Arshad, F., Khurshid, F. (2018): Evaluation Of Low Cost Environment Friendly Natural Extracts For The Purification Of Drinking Water. - Earth Sciences Pakistan 2(1): 23-25.

[23] Niu, Z. Q., Wang, H. B., Hou, J. Q., Yan, J., Lu, Z. Y. (2002): Basic Theory for the Effects of Electromagnetic wave on Ion Concentration in Cells. - Chinese Journal of Biomedical Engineering 21(6): 552-556.

[24] Patle, G. T., Sikar, T. T., Rawat, K. S., Singh, S. K. (2019): Estimation of infiltration rate from soil properties using regression model for cultivated land. - Geology, Ecology, and Landscapes 3(1): 1-13.

[25] Plonsey, R., Barr, R. C. (2000): Bioelectricity, A Quantitative Approach. - New York: Kluwer Academic 201-235.

[26] Richard, S. L., Stephen, B. (1998): Dielectric studies of chain melting and denaturation in native DNA. - Biochimica Biophysica Acta 1397: 316-324.

[27] Sen, B., Goswami, S., Devi, G., Sarma, H. P., Bind, A. (2018): Valorization of Adenanthera pavonina seeds as a potential biosorbent for lead and cadmium removal from single and binary contaminated system. - Geology, Ecology, and Landscapes 2(4): 275-287.

[28] Shan, P. F., Lai, X. P. (2018): Numerical Simulation of the Fluid-Solid Coupling Process During the Failure of a Fractured Coal-Rock Mass Based on the Regional Geostress. Transport in Porous Media 124(3): 1061-1079.

[29] Suhaili, M. Z., Samsudin, M. D. M. (2018): Utilization Of Wastewater For Corrosion Prevention Of Carbon Steel Pipe Using Single Chamber Microbial Fuel Cells. Environment \& Ecosystem Science 2(2): 47-52.

[30] Tadej, K., Damijan, M. (2000): Second-order model of membrane electric field induced by alternating external electric fields. - IEEE Transactions on Biomedical Engineering 47(8): 1074-1081.

[31] Tao, S. (2018): Evaluation Of Technology Innovation In Hubei Province. - Engineering Heritage Journal 2(2): 09-10.

[32] Yahya, N., Aziz, F., Enriquez, M. A. O., Aizat, A., Jaafar, J., Lau, W. J., Yusof, N., Salleh, W. N. W., Ismail, A. F. (2018): Preparation And Characterization Of Lafeo3 Using Dual-Complexing Agents For Photodegradation Of Humic Acid. - Environment \& Ecosystem Science 2(2): 30-34.

[33] Yang, B., Luo, Y., Jeng, D., Feng, J., Huhe, A. (2018): Experimental studies on initiation of current-induced movement of mud. - Applied Ocean Research 80: 220-227.

[34] Yang, B., Gao, F. P., Jeng, D. S. (2018): Failure mode and dynamic response of a doublesided slope with high water content of soil. - Journal of Mountain Science 15(4): 859870 . 
[35] Yanyan, D., Fuwen, D., Yue, L. (2019): Effect of Sewage Load on Microenvironment and Sludge Reduction Efficiency of Situ Biofilm Sludge Reduction System. - Acta Microscopica 28(2).

[36] Zhai, Y. R., Li, J. H., Zhang, H. (1998): Experiment of high physics. - Shenyang: Liaoning University Publisher 101-107.

[37] Zhang, G. C. H. (1998): Cell biology. - Beijing: High Education Publisher 18-61.

[38] Zhang, X. (2002): UV-Desinfection in Wastewater Treatment. - Water and Wastewater Engineering 28(11): 31-34.

[39] Zhang, H. J., Xu, D., Niu, Z. H. Q. (2004): A Response of the Probability Crossing Cell Membrane to the Electromagnetic Wave. - Chinese Journal of Medical Physics 21(3): 179-181.

[40] Zhang, W., Yang, J., Fang, Y., Chen, H., Mao, Y., Kumar, M. (2017): Analytical fuzzy approach to biological data analysis. - Saudi journal of biological sciences 24(3): 563573.

[41] Zhao, X. F. (2016): Research and application status of urban sewage treatment technology. - Liaoning Chemical 45(10): 1338-1340.

[42] Zhou, W. H., Zhang, J. (2000): Study on the Sterilization Technology of Electromagnetic Pulse. - Journal of Microwaves 16(3): 318-321. 